\title{
The role of FIS protein in the physiological control of the expression of the Escherichia coli meta-hpa operon
}

\section{Correspondence \\ Beatriz Galán \\ bgalan@cib.csic.es}

Received 12 December 2007

Revised 13 March 2008

Accepted 14 March 2008

\author{
Beatriz Galán, ${ }^{1}$ Isabel Manso, ${ }^{1}$ Annie Kolb, ${ }^{2}$ José Luis García ${ }^{1}$ \\ and María A. Prieto ${ }^{1}$ \\ ${ }^{1}$ Department of Molecular Microbiology, Centro de Investigaciones Biológicas, CSIC, Madrid, Spain
${ }^{2}$ Unité de Génétique Moléculaire-URA 2172, Institut Pasteur, Paris, France
}

Expression from the Escherichia coli W meta-hpa operon promoter $(P g)$ is under a strict catabolic repression control mediated by the cAMP-catabolite repression protein (CRP) complex in a glucose-containing medium. The $P g$ promoter is also activated by the integration host factor (IHF) and repressed by the specific transcriptional regulator $\mathrm{HpaR}$ when 4-hydroxyphenylacetate (4HPA) is not present in the medium. Expression from the hpa promoter is also repressed in undefined rich medium such as LB, but the molecular basis of this mechanism is not understood. We present in vitro and in vivo studies to demonstrate the involvement of FIS protein in this catabolic repression. DNase I footprinting experiments show that FIS binds to multiple sites within the $\mathrm{Pg}$ promoter. FIS-site I overlaps the CRP-binding site. By using an electromobility shift assay, we demonstrated that FIS efficiently competes with CRP for binding to the $P g$ promoter, suggesting an antagonist/competitive mechanism. RT-PCR showed that the $P g$ repression effect is relieved in a FIS deleted strain. The repression role of FIS at $P g$ was further demonstrated by in vitro transcription assays. These results suggest that FIS contributes to silencing the $P g$ promoter in the exponential phase of growth in an undefined rich medium when FIS is predominantly expressed.

\section{INTRODUCTION}

The hpa cluster of Escherichia coli W was the first aromatic catabolic pathway described at a molecular level in this enterobacterium and codes for a group of proteins involved in the degradation of 4-hydroxyphenylacetate (4HPA) and 3-hydroxyphenylacetate (3HPA) (Prieto et al., 1996) (Fig. 1). The catabolic genes are organized in two operons: the $h p a B C$ operon encoding the paradigmatic two-component 4HPA monooxygenase which transforms 4HPA or 3HPA into 3,4-dihydroxyphenylacetic acid (HPC) (Galán et al., 2000; Prieto \& García, 1994; Prieto et al., 1993), and the meta operon (hpaGEDFHI), which codes for the enzymes cleaving the aromatic ring of HPC and allowing its complete mineralization (Prieto et al., 1996; Roper et al., 1993). The transcription of the hpa cluster is controlled by the products of the $h p a A$ and $h p a R$ genes (Fig. 1) (Prieto \& García, 1997). HpaA is an activator belonging to the XylS/AraC family of regulators, which controls the expression of the upper operon ( $\mathrm{Pbc}$ promoter) (Prieto \& García, 1997), whereas HpaR is a member of the

Abbreviations: CRP, catabolite repression protein; EMSA, electromobility shift assay; FIS, factor for inversion stimulation; HPA, hydroxyphenylacetate; HPC, 3,4-dihydroxyphenylacetic acid; IHF, integration host factor; RNAP, RNA polymerase; RT-PCR, reverse transcriptase PCR.
MarR family (Prieto \& García, 1997; Galán et al., 2003) which represses both the expression of the meta operon $(\mathrm{Pg}$ promoter) (Galán et al., 2001; Roper et al., 1993) and its own expression ( $P r$ promoter) (Galán et al., 2003). While 4HPA was able to induce $P b c, P r$ and $P g$ promoters, HPC only induces the $P g$ and $P r$ promoters (Fig. 1). In addition to this specific regulatory system, we have previously demonstrated that the expression of the $P g$ promoter is controlled by a very unusual strict catabolite repression mechanism mediated by the common global regulators, the catabolite repression protein (CRP) and the integration host factor (IHF), connecting the physiological status of the cell to the specific induction of the hpa genes (Galán et al., 2001). Although $P g$ is not a $\sigma^{38}$-dependent promoter, it is activated in the stationary phase when cells are cultured with glucose as the sole carbon and energy source. In the current study, we present in vivo and in vitro data concerning the performance of the $P g$ promoter in rich medium. By using a $P g:$ : lacZ translational fusion and quantitative RT-PCR we have shown that the $h p a$ regulatory system is under repression control and that this effect is cAMP-CRP dosage-independent, indicating that the $h p a$ regulatory system is still more complex than previously envisioned. Our results reveal that the FIS regulator plays an important role in this effect. 
(a)

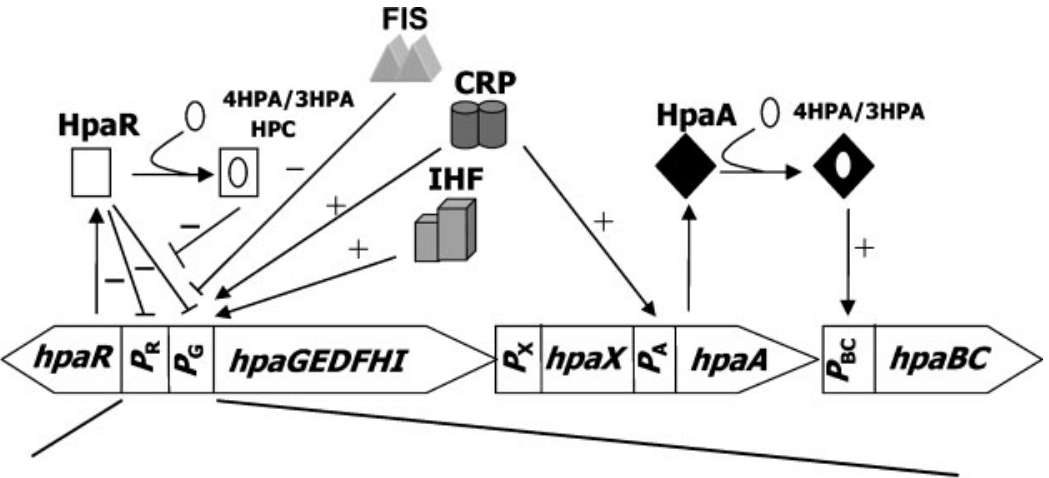

(b)

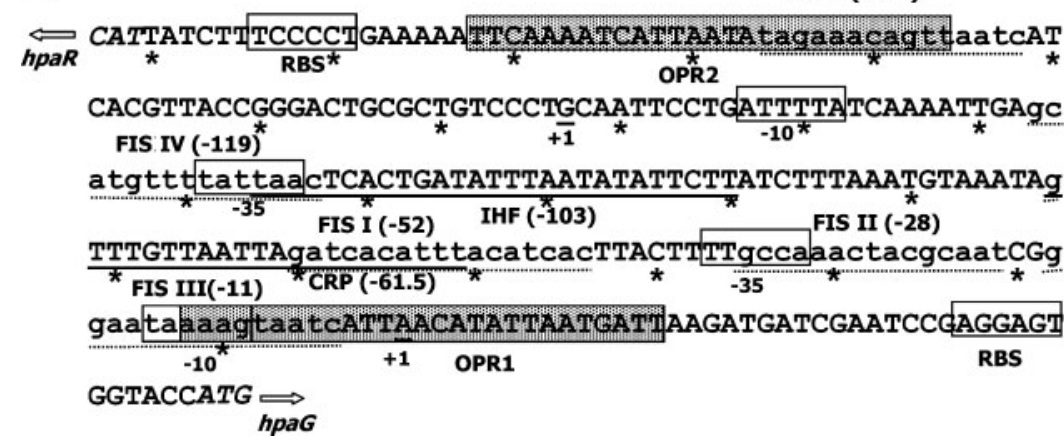

Fig. 1. (a) Regulation of the hpa cluster. The catabolic (hpaBCDEFGHI), transport (hpaX) and regulatory genes ( $h p a A$ and $h p a R)$ of the hpa cluster are represented. The block arrows indicate the directions of gene transcription. $\mathrm{Pr}, \mathrm{Pg}, \mathrm{Px}, \mathrm{Pa}$ and $\mathrm{Pbc}$ are promoter regions. $\square$, Active form of HpaR repressor; $>$, inactive form of $\mathrm{HpaA}$ activator; $\bigcirc$ inducer. Transcriptional repression (-) and activation (+) are indicated. (b) Sequence of the $h p a R$ hpaG intergenic region. $P g$ and $\operatorname{Pr}$ promoter boxes -35 and -10 and the ribosome-binding sites (RBS) are indicated as white boxes. The transcription start site of $P g$ and $\operatorname{Pr}(+1), C R P$ and IHF sites are underlined with a continuous line. ATG start codons of $h p a R$ and $h p a G$ are shown in italics. An asterisk has been placed every $10 \mathrm{nt}$ from +1 of $\mathrm{Pg}$. The OPR 1 and OPR2 operators for $\mathrm{HpaR}$ are boxed in grey. FIS sites (I-V) detected by in vitro binding are indicated in upper case and dotted underlined.

\section{METHODS}

Bacterial strains, plasmids and culture conditions. The strains and plasmids used throughout this study are listed in Table 1. To overexpress the crp gene, the 702 bp EcoRI-HindIII fragment from plasmid pDCRP (Bell et al., 1990), carrying the structural crp gene without the promoter region, was cloned into pUC19 treated with the same endonucleases, to yield the plasmid pBeBe. Strains carrying the $P g$ : : lacZ fusion were constructed and validated previously (Galán et al., 2001). Reporter fusions were inserted into the chromosome of the target strains by the pUT-Km miniTn 5 delivery system (Herrero et al., 1990), which allows the generation of reporter strains carrying translational fusions with the lac $Z$ gene that are stably inserted into their chromosome. The selection of each reporter strain was made among three different candidates with similar expression levels to avoid $P g$-unrelated lacZ expression. Cells were grown aerobically in Luria-Bertani medium (LB) at $30{ }^{\circ} \mathrm{C}$, to be consistent with data related to aromatic compound metabolism in E. coli W (Prieto et al., 1996; Galán et al., 2001, 2004). When needed, antibiotics were added at the following concentrations: ampicillin, $100 \mu \mathrm{g} \mathrm{ml}^{-1}$; kanamycin, $50 \mu \mathrm{g} \mathrm{ml}^{-1}$; rifampicin, $50 \mu \mathrm{g} \mathrm{ml}^{-1}$; and streptomycin, $50 \mu \mathrm{g} \mathrm{ml}^{-1}$. General procedures for DNA manipulations were performed as indicated elsewhere (Sambrook \& Russell, 2001).

Construction of a FIS null mutant of $\boldsymbol{E}$. coli W. The fis gene was inactivated by marker exchange as described by Kaniga et al. (1991), using the mobilizable suicide plasmid pKNG $\Delta$ fis (Table 1). Deletion of the fis gene was engineered with the DNA fragments fis 5 and fis 3 of 313 and 280 bp respectively, generated by PCR using the primer pairs FISMUT5/FISNcoI for fis5 and FISMUT3/FISAflIII for fis3 (Table 1). These two fragments were digested with the appropriate restriction enzymes and ligated using T4 ligase, resulting in a single 593 bp fragment carrying a $332 \mathrm{bp}$ deletion in the fis gene, which was cloned into the unique BamHI and SmaI sites of pKNG101 to yield $\mathrm{pKNG} \Delta$ fis. Plasmid $\mathrm{pKNG} \Delta$ fis was used to deliver the fis mutation to the host chromosome via homologous recombination. Biparental mating was performed following protocols described by de Lorenzo \&
Timmis (1994) using E. coli SM10/pir (pKNG $\Delta$ fis) as donor and $E$. coli $\mathrm{W}$ as recipient. For conjugation, $100 \mu \mathrm{l}$ of overnight cultures of donor and recipient strains were mixed in $5 \mathrm{ml} 10 \mathrm{mM} \mathrm{MgSO}_{4}$ and collected on a Millipore filter, which was subsequently placed on an LB agar plate and incubated overnight at $30{ }^{\circ} \mathrm{C}$. After incubation, the cells were resuspended in $5 \mathrm{ml} 10 \mathrm{mM} \mathrm{MgSO}_{4}$ and plated on M63 selective plates supplemented with $5 \%$ sucrose as described previously (Kaniga et al., 1991). Transconjugants $\left(\mathrm{Suc}^{\mathrm{r}} \mathrm{Sm}^{\mathrm{s}}\right.$ ) were isolated. The second crossover event was confirmed by PCR using primers FISMUT5 and FISMUT3 (Table 1). The resultant mutant strain was denoted W16 (Table 1).

Assay for $\boldsymbol{\beta}$-galactosidase. An overnight culture of cells harbouring the $P g$ : : lac $Z$ translational fusion grown in LB medium was diluted $1: 10$ in fresh medium and incubated at $30^{\circ} \mathrm{C}$. If required, the inducer 4HPA was added at $1 \mathrm{mM}$. Aliquots were collected at different cell densities for the $\beta$-galactosidase activity determination according to the method described by Miller (1972). At least three independent assays were performed in each case.

Protein techniques. SDS-PAGE was by standard methods (Sambrook \& Russell, 2001). Aliquots containing E. coli cell suspensions at similar $\mathrm{OD}_{600}$ values were lysed in phosphate buffer pH 7.5 with $2 \%$ SDS and $5 \% \beta$-mercaptoethanol, and run in denaturing $17.5 \%$ polyacrylamide gels. For Western blot analysis, these gels were subsequently blotted and probed with a $1: 1000$ dilution of a mouse polyclonal antiserum against IHF protein of Pseudomonas putida kindly provided by V. de Lorenzo (Centro Nacional de Biotecnología-CSIC, Spain). The anti-IHF antiserum was pre-absorbed with a 1:10 dilution of E. coli crude extract. The band corresponding to this protein was developed with the ECL Western Blotting Detection kit (Amersham Biosciences) according to the protocol described by the manufacturer.

DNase I protection experiments. For DNase I footprinting experiments, the $314 \mathrm{bp} h p a G-h p a R$ DNA fragment that was used as a probe was amplified by PCR with primers PG5 and PG3 using $10 \mathrm{ng}$ 
Table 1. Bacterial strains, plasmids and oligonucleotides with relevant genotype and phenotype

\begin{tabular}{|c|c|c|}
\hline $\begin{array}{l}\text { Strain, plasmid or } \\
\text { oligonucleotide }\end{array}$ & Relevant genotype or phenotype & Source or reference \\
\hline \multicolumn{3}{|l|}{ E. coli $\mathrm{K}-12$} \\
\hline MC4100 & $\mathrm{F}^{-}$araD319 $\Delta(\operatorname{argF}-$ lac $) U 169$ relA1 flbB5301 deoC1 ptsF25 rbsR & Prieto \& García (1997) \\
\hline MCG11 & MC4100 with chromosomal insertion of mini-Tn5 Km $P g:: l a c Z, \mathrm{Km}^{\mathrm{r}} \mathrm{Rif}^{\mathrm{r}}$ & Galán et al. (2001) \\
\hline CC118( $(\lambda$ pir $)$ & Host for pUT-derived plasmids, Rif ${ }^{r}$ & Herrero et al. (1990) \\
\hline SBPG11 & 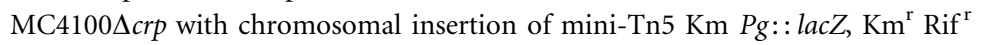 & Galán et al. (2001) \\
\hline S90CRif & $(\Delta l a c, p r o) \operatorname{rps} L, \mathrm{Sm}^{\mathrm{r}} \operatorname{Rif}^{\mathrm{r}}$ & Ferrández et al. (2000) \\
\hline S90G11 & S90CRif with chromosomal insertion of mini-Tn5 Km Pg: : lacZ, $\mathrm{Km}^{\mathrm{r}} \mathrm{Rif}^{\mathrm{r}}$ & Galán et al. (2001) \\
\hline DBP101Rif & S90C himD451:: mini-tet, $\operatorname{Rif}^{\mathrm{r}} \mathrm{Tc}^{\mathrm{r}} \mathrm{Sm}^{\mathrm{r}}$ & Ferrández et al. (2000) \\
\hline DBPG11 & DBP101Rif with chromosomal insertion of mini-Tn5 Km $P g:$ : lacZ, $\mathrm{Km}^{\mathrm{r}} \mathrm{Rif}^{\mathrm{r}}$ & Galán et al. (2001) \\
\hline \multicolumn{3}{|c|}{ 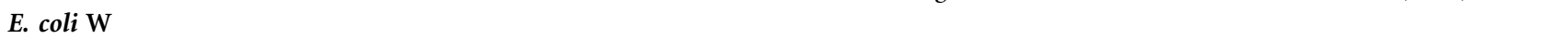 } \\
\hline WPG11 & $\begin{array}{l}\text { W14 derivative, } \Delta p a a \quad \Delta l a c Z \text { with chromosomal insertion of mini-Tn5 Km } \\
P g:: l a c Z, \mathrm{Km}^{\mathrm{r}} \text { Rif }^{\mathrm{r}}\end{array}$ & Galán et al. (2001) \\
\hline W16 & W derivative $\Delta$ fis & This work \\
\hline \multicolumn{3}{|l|}{ Plasmids } \\
\hline pUC19 & Cloning vector & Sambrook \& Russell (2001) \\
\hline pBR322 & Cloning vector & Sambrook \& Russell (2001) \\
\hline pDCRP & pBR322 derivative carrying the structural $c r p$ gene & Bell et al. (1990) \\
\hline $\mathrm{pBeBe}$ & pUC19 with 702 bp EcoRI/HindIII fragment from pDCRP carrying the crp gene & This work \\
\hline $\mathrm{pP}_{\mathrm{L}}$ hip.himA-5 & $\mathrm{Ap}^{\mathrm{r}}, \operatorname{himA}$ hip & Nash et al. (1987) \\
\hline pAJ40 & pUC18 derivative containing $h p a$ cluster, $\mathrm{Ap}^{\mathrm{r}}$ & Prieto et al. (1993) \\
\hline pBM1 & pUJ9 derivative, $P g:$ : lac $Z, \mathrm{Ap}^{\mathrm{r}}$ & Galán et al. (2001) \\
\hline pBF1 & $h p a R-h p a G$ region flanked by transcriptional terminators & Galán et al. (2003) \\
\hline pKNG101 & $\mathrm{Sm}^{\mathrm{r}} \mathrm{Mob}^{+}$, sacBR, R6K replicon & Kaniga et al. (1991) \\
\hline pKNG $\Delta$ fis & $\begin{array}{l}\text { pKNG101 derivative carrying the } 3^{\prime} \text { end of gene } y h d G \text { and } 5^{\prime} \text { end of gene } y h d J \\
\text { from E. coli }\end{array}$ & This work \\
\hline Oligonucleotides & Sequence $\left(5^{\prime}-3^{\prime}\right)$ & \\
\hline PG5 & gcaagaattcgtgagtcgtgcattatctttcccc & \\
\hline PG3 & gatagtgggatccatggtaccactcctcggattcgatc & \\
\hline FISMUT3 & tccccogggcactctgcaatcacttcaaacagc & \\
\hline FISMUT5 & cgggatccggaaatccagcattatctggacac & \\
\hline FISNcoI & catgccatgggtacgtcagaatttacgcgttgttcg & \\
\hline FISAflIII & cccacatgtgcttgattaaaaaggcgctactcg & \\
\hline HpaG5 & cggatatgcgctggctaacgatgtc & \\
\hline HpaG3 & gcggtgttccagtgatcggcagg & \\
\hline PGDE & ccggaattctgtaaatagtttgttaattag & \\
\hline
\end{tabular}

plasmid pAJ40 (Table 1) as a template. Both strands were alternately labelled using a combination of one unlabelled primer and a second primer end-labelled with phage T4 polynucleotide kinase $\left[\gamma_{-}^{32} \mathrm{P}\right] \mathrm{ATP}$ (111 TBq $\mathrm{mmol}^{-1}$ ). Then the PCR fragment was purified using the High Pure PCR Product Purification kit from Boehringer Mannheim as described by Galán et al. (2001). Complexes with the labelled promoter region ( $1 \mathrm{nM}$ final concentration of DNA) were formed for $20 \mathrm{~min}$ at room temperature in $15 \mu \mathrm{l}$ of a glutamate buffer solution (40 mM HEPES pH 8.0, $10 \mathrm{mM} \mathrm{MgCl}_{2}, 2 \mathrm{mM}$ DTT, $100 \mathrm{mM}$ potassium glutamate) containing $500 \mu \mathrm{g} \mathrm{BSA} \mathrm{ml} \mathrm{m}^{-1}$ and FIS protein (kindly provided by G. Muskhelishvili, International University Bremen, Germany). Then $3 \mu \mathrm{l}$ of DNase I solution (0.15 units in $10 \mathrm{mM}$ Tris/ $\mathrm{HCl} \mathrm{pH} 8,10 \mathrm{mM} \mathrm{MgCl}, 125 \mathrm{mM} \mathrm{KCl}$ ) was added and incubated at $37^{\circ} \mathrm{C}$ for $20 \mathrm{~s}$. The reaction was stopped by the addition of $180 \mu \mathrm{l}$ of a solution containing $0.4 \mathrm{M}$ sodium acetate, $2.5 \mathrm{mM}$ EDTA, $50 \mu \mathrm{g}$ tRNA ml ${ }^{-1}$ and $5 \mu \mathrm{g}$ salmon sperm DNA ml${ }^{-1}$. The samples were extracted with phenol and precipitated with ethanol before analysis on a $7 \%(\mathrm{v} / \mathrm{v})$ denaturing polyacrylamide gel. Protected bands were identified by comparison with the migration of the same fragment treated for the A $+\mathrm{G}$ sequencing reaction (Maxam \& Gilbert, 1977).
Competition gel retardation assays. For the labelling of the probe in competition gel retardation assays, a DNA fragment of $147 \mathrm{bp}$ containing the $P g$ promoter was amplified by PCR using $10 \mathrm{ng}$ of plasmid pAJ40 (Table 1) as template and a combination of one unlabelled primer and the second primer $5^{\prime}$ end-labelled with phage T4 polynucleotide kinase $\left[\gamma^{-32} \mathrm{P}\right] \mathrm{ATP}\left(111 \mathrm{TBq}^{\mathrm{mmol}}{ }^{-1}\right)$. The primers used were PG3 and the labelled primer PGDE (Table 1). The reaction mixtures (final volume $20 \mu \mathrm{l}$ ) contained $9 \mu \mathrm{l}$ glutamate buffer solution with $500 \mu \mathrm{g} \mathrm{BSA} \mathrm{ml}{ }^{-1}, 0.5 \mathrm{nM}$ DNA probe and purified CRP and FIS proteins. After incubation for $20 \mathrm{~min}$ at room temperature, mixtures were fractionated by electrophoresis in $7.5 \%$ polyacrylamide gels buffered with $1 \times$ TBE ( $45 \mathrm{mM}$ Tris/borate, 1 mM EDTA). The gels were dried onto Whatman $3 \mathrm{MM}$ paper and exposed to Hyperfilm MP (Amersham Pharmacia Biotech).

Run-off transcription assays. Single-round transcription by E. coli RNA polymerase (RNAP) was carried out under standard conditions (Marschall et al., 1998), using buffer B (40 mM Tris/ $\mathrm{HCl} \mathrm{pH} \mathrm{8.0,}$ $10 \mathrm{mM} \mathrm{MgCl}_{2}, 100 \mathrm{mM} \mathrm{KCl}, 200 \mu \mathrm{M} \mathrm{cAMP}$ and $500 \mu \mathrm{g} \mathrm{BSA} \mathrm{ml}^{-1}$ ) and supercoiled DNA plasmid pBF1 (Table 1). The final volume of the reaction mixture was $9 \mu \mathrm{l}$, containing the plasmid DNA $(5 \mathrm{nM})$ 
with either CRP (100 nM) and FIS (100-1000 nM) or buffer. This mixture was incubated at room temperature for $20 \mathrm{~min}$. Then, $3 \mu \mathrm{l}$ RNAP at $375 \mathrm{nM}$ in buffer $\mathrm{B}$ was added and the mixture was incubated at $37{ }^{\circ} \mathrm{C}$ for $5 \mathrm{~min}$ in a final volume of $12 \mu$. Elongation was started by the addition of $3 \mu \mathrm{l}$ pre-warmed mixture $(1 \mathrm{mM}$ ATP, $1 \mathrm{mM}$ GTP, $1 \mathrm{mM}$ CTP, $50 \mu \mathrm{M}$ UTP, $37 \mathrm{kBq}$ of $\left[\alpha_{-}{ }^{32}\right] \mathrm{UTP}$ and $500 \mu \mathrm{g}$ heparin $\mathrm{ml}^{-1}$ in buffer B) to the template-polymerase mix. The reactions were allowed to proceed for $5 \mathrm{~min}$ at $37^{\circ} \mathrm{C}$ and were stopped by the addition of $12 \mu \mathrm{l}$ loading buffer (see above) containing $1 \%$ SDS. After heating to $70{ }^{\circ} \mathrm{C}$, samples were subjected to electrophoresis on $7 \%$ sequencing gels. Run-off products were quantified using a PhosphorImager (Molecular Dynamics).

Real-time RT-PCR assay. Total RNA was extracted from E. coli W and E. coli W16 cells that were inoculated at $\mathrm{OD}_{600}$ of 0.05 in $\mathrm{LB}$ medium containing $1 \mathrm{mM}$ 4HPA. Cells were harvested throughout the growth curve $\left(\mathrm{OD}_{600}\right.$ values of $0.05,0.2,0.9,1.8,3$ and 4$)$ and stored at $-20{ }^{\circ} \mathrm{C}$. Pellets were thawed and cells lysed in TE buffer (10 mM Tris/ $\mathrm{HCl} \mathrm{pH} 7.5,1 \mathrm{mM}$ EDTA) containing $5 \mathrm{mg}$ lysozyme $\mathrm{ml}^{-1}$ by a series of freeze/thaw cycles. RNA was extracted using the RNeasy mini kit (Qiagen), including a DNase I treatment according to the manufacturer's instructions, precipitated with ethanol, washed and resuspended in $40 \mu \mathrm{l}$ RNase-free water. The concentration and purity of the RNA samples were measured by using a ND1000 spectrophotometer (Nanodrop Technologies). Synthesis of total cDNA was carried out with $20 \mu \mathrm{l}$ reverse transcription reactions containing $1 \mu \mathrm{g}$ RNA, $0.5 \mathrm{mM}$ dNTPs, $200 \mathrm{U}$ SuperScript II Reverse Transcriptase (Invitrogen) and $5 \mu \mathrm{M}$ of random hexamers as primers, in the buffer recommended by the manufacturer. Samples were initially heated at $65{ }^{\circ} \mathrm{C}$ for $5 \mathrm{~min}$ and then incubated at $42{ }^{\circ} \mathrm{C}$ for $1 \mathrm{~h}$, terminated by incubation at $70{ }^{\circ} \mathrm{C}$ for $15 \mathrm{~min}$. The cDNA obtained was purified using Geneclean Turbo kit (MP Biomedicals) and the concentration was measured using a ND100 Spectrophotometer (Nanodrop Technologies). For the analysis of the transcript levels from the $P g$ promoter, target cDNAs $(0.5,2$ and $5 \mathrm{ng}$ ) and reference samples were amplified three times in separate PCR with $0.2 \mu \mathrm{M}$ each of HpaG5 and HpaG3 primers by using the iQ5 Multicolor Real-Time PCR Detection System (Bio-Rad). Realtime PCR was performed using SYBR Green technology in an ABI Prism 7000 Sequence Detection System (Applied Biosystems). Samples were initially denatured by heating at $95{ }^{\circ} \mathrm{C}$ for $4 \mathrm{~min}$, followed by 30 cycles of amplification $\left(95^{\circ} \mathrm{C}, 1 \mathrm{~min}\right.$; test annealing temperature, $65{ }^{\circ} \mathrm{C}, 1 \mathrm{~min}$; elongation and signal acquisition, $72{ }^{\circ} \mathrm{C}$, $30 \mathrm{~s}$ ). For relative quantification of the fluorescence values, a calibration curve was made using dilution series from 200-0.2 ng of E. coli $\mathrm{W}$ genomic DNA sample.

\section{RESULTS}

\section{Monitoring the $\mathbf{P g}$ expression profile in rich medium}

To investigate the expression profile of the $P g$ promoter in undefined rich medium, we have exploited the E. coli reporter strain WPG11 $\left(P g:: \operatorname{lacZ}, h p a^{+}\right)$as a reliable system (Galán et al., 2001). E. coli WPG11 cells were cultured in LB for $10 \mathrm{~h}$ in the presence and absence of $4 \mathrm{HPA}$ as inducer, and the $\beta$-galactosidase activity was determined along the growth curve (Fig. 2a). As expected, $\mathrm{Pg}$ expression was negligible both in the exponential and in the stationary phases of growth when 4HPA was not added to the medium. $\beta$-Galactosidase levels were also low (40-60 Miller units) during the exponential phase of growth in the presence of 4HPA and they increased 2.8-fold at the onset of the stationary phase, i. e. after approximately 5-6 h of growth. These results strongly suggested that the promoter of this aromatic catabolic pathway was under strong repression when cells were growing in rich medium. It was initially assumed that a putative mechanism that could explain the observed $P g$ repression in the exponential phase may be mediated by an overexpression of the HpaR repressor, which in turn might produce an over-repression effect. To analyse this possibility, we monitored the $\mathrm{Pg}$ activity in an E. coli MCG11 that naturally lacks the $h p a$ cluster ( $\mathrm{hpa}^{-}$) (Galán et al., 2001) (Fig. 2b). As expected, the levels of $\beta$-galactosidase were fourfold higher in the absence of repressor (Fig. 2). Additionally, Fig. 2(b) shows that the repression at exponential phase of $P g$ activity can be reproduced in the reporter E. coli K-12 strain MCG11 $\left(h p a^{-}, P g:: l a c Z\right)$ (Table 1). Since this strain does not contain the HpaR repressor or any other hpa gene product, we can conclude that the factors involved in the physiological control of $\mathrm{Pg}$ promoter at exponential phase
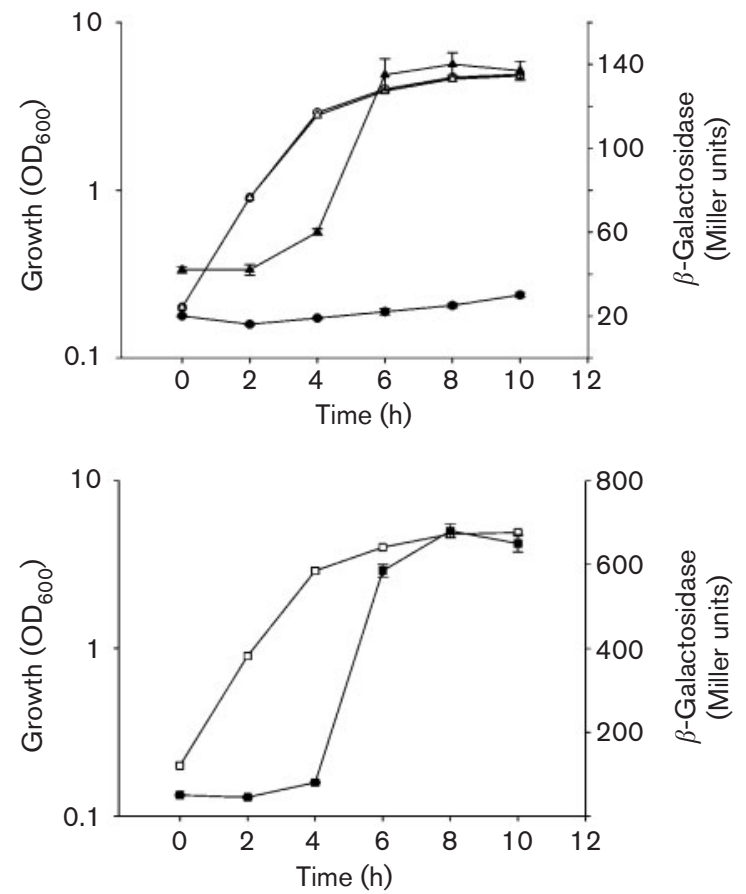

Fig. 2. Induction of the $P g$ promoter in rich medium. E. coli WPG11 (a) and E. coli MCG11 (b) harbouring a $P g$ : : lacZ fusion integrated into the chromosome were grown for $10 \mathrm{~h}$ in LB medium. Aliquots were taken at different times, and $\beta$-galactosidase activity (filled symbols) was measured. Growth is indicated as open symbols. (a) E. coli WPG11 carries the hpaR gene into the chromosome; therefore cells were grown at $30{ }^{\circ} \mathrm{C}$ in the presence $(\triangle, \mathbf{\Delta})$ and absence $(\bigcirc, \boldsymbol{0})$ of the inducer $1 \mathrm{mM} 4 \mathrm{HPA}$. (b) E. coli MCG11 cells growing at $30{ }^{\circ} \mathrm{C}$ in the absence of the inducer $(\square$, ש). Error bars represent standard deviation calculated from the results of three independent experiments (not shown where smaller than symbols). 
in E. coli W $\left(h_{p a} a^{+}\right)$are also present in E. coli K-12 ( $\left.h p a^{-}\right)$. Therefore, this effect may be due to global regulators of the host cell rather than to specific hpa genes.

\section{Influence of the global regulators IHF and CRP on the $\boldsymbol{P g}$ repression effect in rich medium}

As mentioned above, the superimposed regulation of the $\mathrm{Pg}$ promoter in a glucose-containing medium is mediated by a very severe regulatory system driven by the global regulators IHF and CRP (Galán et al., 2001). Thus, we investigated the involvement of these regulators in the repression effect observed in rich medium. We first analysed the putative role of IHF in the activation of $\mathrm{Pg}$ when cells were growing in LB medium, by measuring the $\beta$-galactosidase activity in the two isogenic strains of $E$. coli DPBG11 ( $\mathrm{IHF}^{-}, \mathrm{Pg}:$ :lacZ) and E. coli S90G11 $\left(\mathrm{IHF}^{+}\right.$, $P g:$ : lacZ) (Table 1). Fig. 3(a) reveals that the absence of IHF strongly reduces $P g$ expression during stationary phase. It is well known that in the transition from the exponential growth phase to the stationary phase, IHF becomes the second-most-abundant protein of the nucleoid, reaching a maximum of 55000 monomers per cell early in stationary phase (Azam \& Ishihama, 1999). Thus, it could be presumed that a reduction of the IHF concentration below a certain threshold would decrease the activity of the $P g$ promoter. To investigate the correlation between the concentration of IHF and the downregulation of $P g$ promoter in the exponential phase, E. coli MCG11 (Pg::lacZ, $\left.h p a^{-}\right)$was transformed with plasmid $\mathrm{pP}_{\mathrm{L}}$ hip.himA-5 (Table 1) to generate E. coli MCG11(pP $\mathrm{L}_{\mathrm{L}}$ hip.himA-5), which overproduces IHF (Nash et al., 1987). The IHF production of this strain was followed along the growth curve by Western blot vs the control MCG11(pBR322) (data not shown). The results shown in Fig. 3(b) demonstrated that the repression of $\mathrm{Pg}$ during exponential phase of cells growing in LB medium was not overcome by the overproduction of IHF. However, as expected, high IHF levels led to an increase in the $\mathrm{Pg}$ activity in the stationary phase. Therefore, we can conclude that the exponential repressing effect observed in rich medium is not caused by a limiting concentration of IHF during this phase of growth. IHF was necessary to activate $P g$ in the stationary phase.

Furthermore, we checked the influence of CRP on the $P g$ activity when cells were cultured in LB by monitoring the $P g$ activity in the isogenic E. coli strains MCG11(pUC19) $\left(\mathrm{CRP}^{+}, \quad P g:\right.$ : lacZ), SBPG11 $\left(\mathrm{CRP}^{-}, \quad P g:\right.$ :lacZ) and MCG11(pBeBe), which overproduces CRP. Overproduction of the CRP protein in MCG11(pBeBe) was followed by SDS-PAGE (data not shown). The lack of CRP in strain SBPG11 led to a complete repression of the $P g$ promoter throughout the growth curve in LB, demonstrating that this global regulator is essential for $\mathrm{Pg}$ transcription. Overexpression of CRP did not alter $\mathrm{Pg}$ expression. Moreover, the external addition of $5 \mathrm{mM}$ cAMP to a culture of the overproducing strain did not have
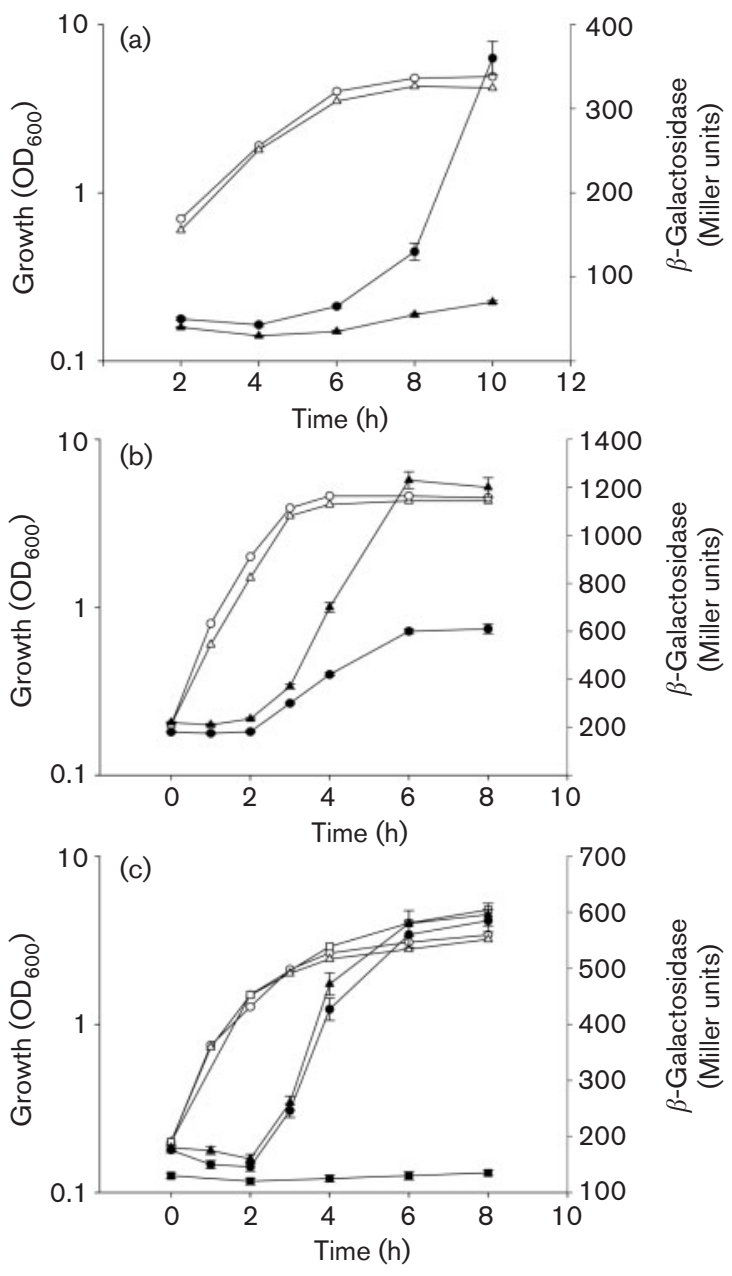

Fig. 3. Influence of the IHF regulator on $P g$ activity. Aliquots of growing cells were taken at different times, and $\beta$-galactosidase activity (filled symbols) and growth (empty symbols) were measured in the E. coli strains (a) DBPG11 $\left(\mathrm{IHF}^{-}\right)(\triangle, \mathbf{\Delta})$ and S90G11 $\left(\mathrm{IHF}^{+}\right)(\bigcirc, 0),(b) \mathrm{MCG} 11(\mathrm{pBR} 322)(\bigcirc, 0)$ and MCG11(pPLhip.him A-5) ( $\triangle, \boldsymbol{\Delta})$, (c) MCG11(pUC19) $(\bigcirc, \boldsymbol{0})$, $\operatorname{MCG} 11(\mathrm{pBeBe})(\triangle, \boldsymbol{\Delta})$ and $\operatorname{SBPG} 11(\square, \boldsymbol{\square})$. Error bars represent standard deviation calculated from the results of three independent experiments (not shown where smaller than symbols).

any effect on $P g$ activity, excluding the involvement of cAMP in this effect (data not shown). Our results indicated that the exponential repressing effect observed in rich medium is not caused by a limiting concentration of CRP during this phase of growth (Fig. 3).

\section{$P g$ repression is relieved in a FIS mutant when cultured in LB medium}

In silico analysis of the $P g$ promoter revealed the presence of a putative factor for inversion stimulation (FIS) binding site located within the $P g$ promoter (see below). FIS is a nucleoid-binding protein involved in global regulatory circuits related to repression of genes that are not required 
under conditions of optimal growth (González-Gil, et al., 1996). It is also well known that FIS acts as a positive regulator of the transcription of the genes that encode stable RNA species, such as rRNA and tRNA (Ross et al., 1990; Bosch et al., 1990; Nilsson \& Emilson, 1994; Gralla, 2005). To investigate the putative role of FIS in the $h p a$ regulatory system, we generated a FIS mutant of the E. coli strain W, named W16 (Table 1). The expression profiles of hpaG, the first gene of the hpa-meta operon (Fig. 1), were monitored and compared throughout the growth curve in strains W and W16. Initially, we studied the $P g$ expression profile in a FIS mutant using the lac $Z$ reporter system. Using this method, the data presented related to CRP and IHF involvement in rich medium were reproducible and reliable. However our statistics were not reproducible in the early exponential growth phase for the FIS mutant carrying $P g$ : : lacZ fusion, resulting in a very high deviation of the data; this was very likely to have been generated by FIS-dependent regulation effects related to the synthesis of the translational machinery. To avoid misinterpretations, real-time RT-PCR was the method selected for these assays. Transcription of $h p a G$ was detected in the wild-type from mid-exponential to stationary phase of growth, reaching a maximum at early stationary phase (Fig. 4). These results are in agreement with those obtained from the reporter strain WPG11 (Fig. 2a) concerning the growth-phasedependent $P g$ expression. However, in the absence of FIS protein, $P g$ expression is detected at an earlier stage of growth, reaching its maximum at the mid-exponential phase. Remarkably, the transcription of $h p a G$ was higher in strain W. In both strains, the $h p a G$ mRNA levels decreased considerably at the end of the stationary phase. However, in the FIS mutant the activity of $P g$ decreased earlier than in the wild-type strain. An explanation for this will require further experimentation. These results strongly suggest that FIS is involved in the $P g$ repression effect observed in rich medium.

\section{FIS binds to the $P g$ promoter}

The ability of purified FIS protein to bind the $h p a R-h p a G$ intergenic DNA region was analysed by DNase I footprinting experiments using the whole hpaR-hpaG DNA region. These experiments showed that FIS bound to this promoter region and revealed the existence of five FIS-binding sites (FIS-site I to V) (Figs 1 and 5a, b). FIS-site I, which is centred at position -52 relative to the $P g+1$ site, overlaps the CRP binding site at position -61.5 , suggesting that the two proteins compete for binding to the $P g$ promoter (Fig. 1). FIS-site II (centred at position -28) and FIS-site III (centred at position -11 ) overlap the -35 and -10 boxes of the $P g$ promoter, respectively, suggesting competition between FIS and the RNAP for Pg binding. Finally, FIS-sites IV and V, centred at positions -119 and -188 , respectively (Fig. 5a, b) could also be involved in the regulation of the divergent $\mathrm{Pr}$ promoter. The binding of FIS to these motifs produces the characteristic DNase I hypersensitive sites, suggesting that it changes the DNA

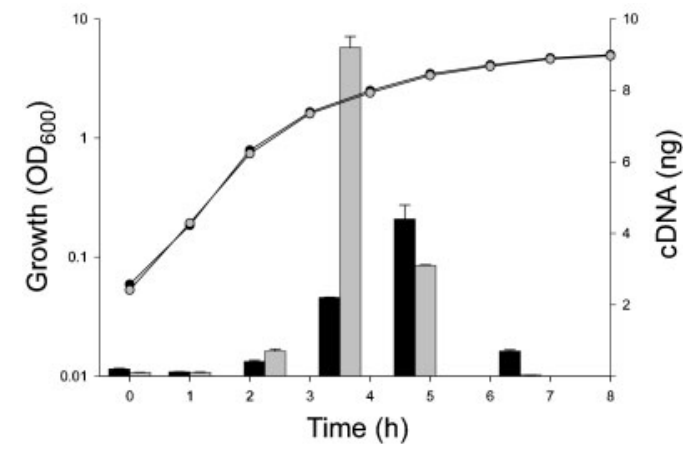

Fig. 4. Effect of FIS on the expression driven by the $P g$ promoter in $E$. coli W and E. coli W16 (fis ${ }^{-}$) strains measured by quantitative RT-PCR. Gene transcription profiles of $h p a G$ throughout growth of E. coli W (black bars and symbols) and W16 (grey bars and symbols) (cultured in LB) are shown; samples along the growth curve were taken at $0,1,2.25,3.5,4.75$ and $6.5 \mathrm{~h}$. An initial concentration of $5 \mathrm{ng}$ cDNA was used for quantitative RT-PCR. Error bars represent standard deviation calculated from the results of three independent experiments.

topology. The concentration of FIS needed to protect site I is $3 \mathrm{nM}$, in contrast to that needed for FIS-sites II to V, which is 10 -fold higher (Fig. $5 \mathrm{a}, \mathrm{b}$ ). Nucleotide sequence comparison of the protected sites with the consensus sequence for the FIS-binding motif (Finkel \& Johnson, 1992; Hengen et al., 1997) allowed the unambiguous definition of the core binding sites as shown in Fig. 5(c). Each binding site differs by one nucleotide to the consensus sequence, except for FIS-site IV, which shows the best match to this consensus.

\section{FIS represses transcription at the $\boldsymbol{P g}$ promoter by a coordinate mechanism involving CRP}

FIS-site I overlaps the CRP-binding site on the $\mathrm{Pg}$ promoter, suggesting that FIS and CRP compete for binding to this DNA region. To investigate this hypothesis we performed a competition gel retardation assay with purified CRP and FIS (Fig. 6a). The addition of FIS alone up to $30 \mathrm{nM}$ generated two different complexes of retarded bands: PG-FIS (1) and PG-FIS (2) (Fig. 6a, lanes 6-8). When FIS was added after CRP binding, the CRP-specific shift decreased as the concentration of FIS increased, and the specific bands for FIS-DNA complexes were detected predominantly. The effect of FIS on transcription initiation at the $P g$ promoter was checked by a single-round in vitro transcription assay using plasmid $\mathrm{pBF} 1$ as template (Table 1), incubated with CRP, RNAP and increasing amounts of FIS (Fig. 6b). When FIS was supplied to the reaction mixture, the $P g$ activity was repressed and only the RNAI control transcript was detected, demonstrating that this protein was able to act as a repressor in vitro. These results suggested a coordinate regulatory mechanism of repression involving at least both CRP and FIS global regulators. 

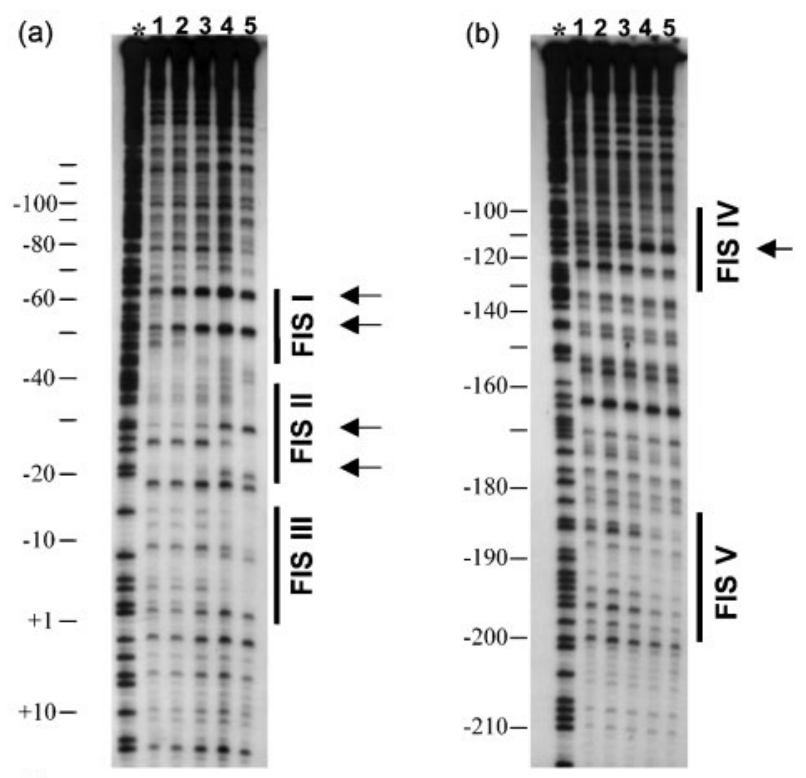

(c)

FIS I
FIS II
FIS III
FIS IV
FIS V
CONSENSUS

$(-52)$

$(-28)$

$(-11)$

$(-119)$

$(-188)$ (b)

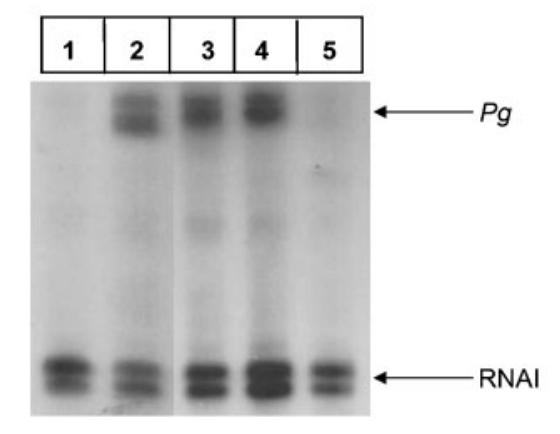

Fig. 5. FIS binding to the $h p a R-h p a G$ intergenic region: DNase I footprinting analysis of the interaction of the FIS protein with the $P g$ promoter region. The reaction mixture was treated as described in Methods, using the $5^{\prime}$-end-labelled non-coding strand (a), and the 5 '-end-labelled coding strand (b) of the hpaR-hpaG intergenic region as probes. DNase I hypersensitivity bands are indicated by arrows. The $A+G$ sequencing ladder is indicated with an asterisk. Lane 1, naked DNA; lane 2, 3 nM FIS; lane 3, 10 nM FIS; lane 4, $30 \mathrm{nM}$ FIS; lane 5, $100 \mathrm{nM}$ FIS. (c) Alignment of the FIS-binding sites and comparison with the consensus FIS-binding motif (Finkel \& Johnson, 1992; Hengen et al., 1997). The more conserved bases are indicated by capital letters, and the less conserved by lower-case letters. The positions that match the consensus sequence are shaded.

\section{DISCUSSION}

Bacterial genes encoding carbon-catabolic enzymes of peripheral metabolism are often regulated in response to the availability of the respective substrate through specific regulatory systems/proteins (Díaz \& Prieto, 2000). However, if a rapidly metabolizable carbon source is additionally present in the growth medium, the production of the peripheral catabolic enzymes can be downregulated until they are required. This general regulatory phenomenon, known as carbon catabolite repression, forms part of the superimposed regulatory systems of catabolic pathways that connect the expression of a peripheral metabolic pathway with the metabolic status of the cell (Cases \& de

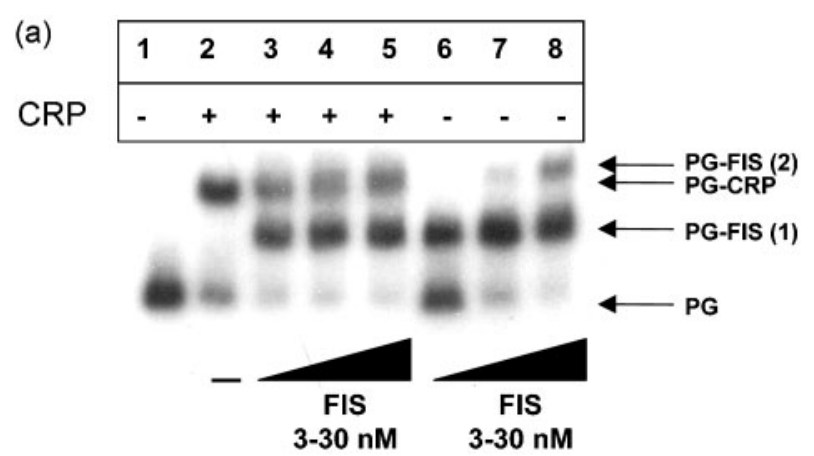

Fig. 6. Repressor role of FIS on the $P g$ promoter. (a) Competition analysis between FIS and CRP in promoter binding. Gel retardation analysis was performed as described in Methods. The presence $(+)$ or absence $(-)$ of $100 \mathrm{nM}$ purified CRP in the reaction mixture is indicated. FIS concentration was $3 \mathrm{nM}$ (lanes 3 and 6), $10 \mathrm{nM}$ (lanes 4 and 7) and $30 \mathrm{nM}$ (lanes 5 and 8). The detected DNA-protein complexes, PG-FIS (1) and PG-FIS (2), PG-CRP, and the position of the corresponding free DNA band, PG, are indicated by arrows. (b) Effect of FIS on Pg-mediated transcription. In vitro transcription analysis was performed as indicated. CRP (lanes 2-5) and RNAP (lanes 1-5) concentrations were $100 \mathrm{nM}$. FIS concentration was $100 \mathrm{nM}$ (lane 3), $300 \mathrm{nM}$ (lane 4), and $1 \mu \mathrm{M}$ (lane 5). The detected transcripts are indicated by arrows. RNAI is an internal control of pBF1.

Lorenzo, 1998; Galán et al., 2001; Prieto et al., 2004). In this study we have further investigated the methods utilized by a paradigmatic micro-organism, E. coli, to control the expression of genes associated with metabolism of aromatic compounds when it detects the presence of preferential carbon sources (Prieto et al., 2004). As a model system, we have used the meta operon of the hpa cluster for the degradation of 4HPA, 3HPA and HPC, whose expression is driven by the $P g$ promoter. The results presented here illustrate that the expression of the $h p a$ genes is controlled by a non-conventional catabolic repression regulatory system when the cells are cultured in an undefined rich medium such as LB, which only favours $h p a$ transcription at the onset of the stationary phase of growth. The classical catabolite repression has been well documented for E. coli, where glucose is the most preferred carbon source, and the phosphotransferase system and the CRP-cAMP complex direct this phenomenon (Busby \& Ebright, 1999; Kolb et al., 1993). Our results suggest that the $P g$ repression effect 
observed when the bacteria are growing in rich medium is mediated by a more complex regulation system and that other global regulators, rather than the ordinary CRPcAMP or even IHF as described previously for the $h p a$ cluster in defined media, are involved in its control (Galán et al., 2001; Prieto et al., 2004). This physiological control is independent of the specific regulatory system of the $h p a$ pathway directed by the HpaR regulator, because several engineered E. coli $h \mathrm{pa}^{-}$reporter strains showed similar $\mathrm{Pg}$ expression profiles to that of the wild-type $h \mathrm{pa}^{+}$strain (Fig. 2). Our results show that FIS binds to multiple sites in the $\mathrm{Pg}$ promoter and negatively regulates the transcription of $h p a$ genes (Fig. 5a, b). FIS interacts with the $P g$ promoter at five FIS sites (I-V) showing different affinities for the $h p a G$-hpaR intergenic region. FIS-sites II and III are centred at positions -28 and -11 with respect to the $\mathrm{Pg}$ transcription initiation site overlapping with the RNAPbinding region at $P g$. FIS-site I overlaps the CRP-binding site in the $P g$ promoter and shows the highest affinity (about 10-fold higher than the other four sites). Finally, FIS-site IV overlaps the IHF binding site at $P g$. FIS is a small nucleoid binding protein that accumulates dramatically in the cell during growth in rich medium, and becomes one of the most abundant DNA-binding proteins in early middle exponential phase; it varies in amount with the growth phase, from fewer than 100 copies in stationary phase to over 50000 copies per cell in exponential phase. However, as cells approach late exponential phase, FIS synthesis ceases, resulting in undetectable levels in the stationary phase (Ball et al., 1992). FIS is known to play a variety of roles at different promoters in E. coli. It is involved in site-specific DNA recombination and participates in the regulation of growth-related genes, assuring the synthesis of the translational machinery in rapid growth (González-Gil et al., 1996; Gralla, 2005). In accordance with its expression profile, FIS is found to directly repress genes that are not required under conditions of optimal growth, such as those whose products are involved in the utilization of alternative carbon sources and nitrate (Xu \& Johnson, 1995; GonzálezGil et al., 1996; Browning et al., 2004b, 2005; Kelly et al., 2004; Bradley et al., 2007). In agreement with this global regulatory function, FIS appears to switch off expression of hpa genes in rich medium when the enzymes for the catabolism of $4 \mathrm{HPA}$ are not required. According to the localization of the FIS binding sites in the $P g$ promoter (Fig. 5), a repression mechanism involving interferences between FIS-RNAP (sites II and III), FIS-IHF (FIS IV) and/ or FIS-CRP (FIS I) binding sites at $P g$ has to be considered. Competitive EMSA indicates that FIS can displace CRP from the FIS I site. In addition, in vitro transcription assays indicate that FIS can inhibit the CRP-dependent transcription activation at the $\mathrm{Pg}$ promoter. A similar mechanism has been previously described for several promoters, including the aldB, acsP2, bgl, hupB and crp promoters from E. coli, driving, respectively, the transcription of genes encoding aldehyde dehydogenase, the acetyl-coenzyme A synthetase, the $\beta$-glucoside operon, the histone-like protein
HU-B and the CRP protein itself (Xu \& Johnson, 1995; Browning et al., 2004a; Caramel \& Schnetz, 2000; Claret \& Rouviere-Yaniv, 1996; González-Gil et al., 1998). In each case, a number of FIS-binding sites which may contribute to repression are located in the promoter region but one of the high-affinity FIS-binding sites overlaps the CRP-binding site, directly occluding the binding of the CRP activator. Interestingly, CRP expression is regulated by this anti-activation mechanism mediated by FIS. FIS represses crp transcription (Gonzalez-Gil et al., 1998) and precludes transcription of the target promoters indirectly by restricting the availability of CRP. FIS also represses its own transcription. Thus, after its initial burst of synthesis, FIS levels drop, derepressing crp transcription. In view of our findings, the repression mechanism could consist of an antagonist/competitive mechanism inhibiting the binding of the CRP activator at the $P g$ promoter. However, a possibility that cannot be excluded is that a FIS multiprotein complex binds throughout the $\mathrm{Pg}$ region (sites IIV) to drive the promoter into a more solid inhibitory structure, also inhibiting the interaction of RNAP and IHF.

Repression in rich medium has also been described in other micro-organisms, e.g. Bacillus (Saier et al., 1995, 1996) and Pseudomonas (Cases \& de Lorenzo, 1998; Dinamarca et al., 2002; Holtel et al., 1994; Yuste \& Rojo, 2001; Petruschka et al., 2001; Sze et al., 1996; Sze \& Shingler, 1999), but the molecular mechanisms involved in repression in these micro-organisms are quite different (Cases \& de Lorenzo, 2000; Cases et al., 1996, 1999; Dinamarca et al., 2002; Moreno et al., 2007).

The metabolic abilities of $E$. coli to cope with aromatic compounds make this bacterium a very useful model system to decipher biochemical, genetic, evolutionary and ecological aspects of this particular type of less-preferred carbon source metabolism (Prieto et al., 2004). The highly strict repression mechanism modulated by FIS, CRP and IHF on the $P g$ promoter of the hpa-meta cluster is quite unusual, since this repression control does not require the presence of specific regulators and it constitutes a fascinating model system to unravel a regulatory network governing the metabolism of less-preferred carbon sources.

\section{ACKNOWLEDGEMENTS}

We thank E. Díaz and M. Carmona for helpful comments and critical reading of the manuscript. We thank Begoña Torres for the help in the construction of plasmid pBeBe. We are indebted to Victor de Lorenzo (Centro Nacional de Biotecnología-CSIC, Spain) for the kind gift of the antibodies against IHF, and to G. Muskhelishvili (International University Bremen, Germany), for the FIS purified protein. This work was supported by Comunidad Autónoma de Madrid Grant AMB-259-0505, by Comisión Interministerial de Ciencia y Tecnología Grants BIO2007-67304-C02 and CTM200604007, by European Union Grants GEN 2006-27750-C5-3-E and NMP2-CT-2007-026515, and by the Programme de Recherche Fondamentale en Microbiologie, Maladies Infectieuses et Parasitaires. 


\section{REFERENCES}

Azam, A. Z. \& Ishihama, A. (1999). Twelve species of DNA-binding protein from Escherichia coli: sequence recognition specificity and DNA binding affinity. J Biol Chem 274, 33105-33113.

Ball, C. A., Osuna, R., Ferguson, K. C. \& Johnson, R. C. (1992). Dramatic changes in FIS levels upon nutrient upshift in Escherichia coli. J Bacteriol 174, 8043-8056.

Bell, A., Gaston, K., Williams, R., Chapman, K., Kolb, A., Buc, H., Minchin, S., Williams, J. \& Busby, S. (1990). Mutations that alter the ability of the Escherichia coli cyclic AMP receptor protein to activate transcription. Nucleic Acids Res 18, 7243-7250.

Bosch, L., Nilsson, L., Vijgenboom, E. \& Verbeek, H. (1990). FISdependent trans-activation of tRNA and rRNA operons of Escherichia coli. Biochim Biophys Acta 1050, 293-301.

Bradley, M. D., Beach, M., de Koning, J., Pratt, T. \& Osuna, R. (2007). Effects of Fis on Escherichia coli gene expression during different growth stages. Microbiology 153, 2922-2940.

Browning, D. F., Beatty, C. M., Sanstad, E. A., Gunn, K. E., Busby, S. J. W. \& Wolfe, A. J. (2004a). Modulation of CRP dependent transcription at the Escherichia coli acsP2 promoter by nucleoprotein complexes: anti-activation by the nucleoid proteins FIS and IHF. Mol Microbiol 51, 241-254.

Browning, D. F., Cole, J. \& Busby, S. (2004b). Transcription activation by remodeling of a nucleoprotein assembly: the role of NarL at the FNR-dependent Escherichia coli nir promoter. Mol Microbiol 53, 203-215.

Browning, D. F., Graninger, D., Beatty, C., Wolfe, A., Cole, J. \& Busby, S. (2005). Integration of three signals at the Escherichia coli nrf promoter: a role for FIS protein in catabolic repression. Mol Microbiol 57, 496-510.

Busby, S. \& Ebright, R. (1999). Transcription activation by catabolite activator protein (CAP). J Mol Biol 293, 199-213.

Caramel, A. \& Schnetz, K. (2000). Antagonistic control of the Escherichia coli bgl promoter by FIS and CAP in vitro. Mol Microbiol 36, 85-92.

Cases, I. \& de Lorenzo, V. (1998). Expression systems and physiological control of promoter activity in bacteria. Curr Opin Microbiol 1, 303-310.

Cases, I. \& de Lorenzo, V. (2000). Genetic evidence of distinct physiological regulation mechanisms in the $\sigma^{54} \mathrm{Pu}$ promoter of Pseudomonas putida. J Bacteriol 182, 956-960.

Cases, I., de Lorenzo, V. \& Pérez-Martin, J. (1996). Involvement of $\sigma^{54}$ in exponential silencing of the Pseudomonas putida TOL plasmid $P u$ promoter. Mol Microbiol 19, 7-17.

Cases, I., Pérez-Martín, J. \& de Lorenzo, V. (1999). The IIANtr (PtsN) protein of Pseudomonas putida mediates the C source inhibition of the sigma54-dependent $P u$ promoter of the TOL plasmid. J Biol Chem 274, 15562-15568.

Claret, L. \& Rouviere-Yaniv, J. (1996). Regulation of HU alpha and HU beta by CRP and FIS in Escherichia coli. J Mol Biol 263, 126-139.

de Lorenzo, V. \& Timmis, K. (1994). Analysis and construction of stable phenotypes in gram-negative bacteria with $\operatorname{Tn} 5-$ and $\operatorname{Tn} 10$ derived minitransposons. Methods Enzymol 235, 386-405.

Díaz, E. \& Prieto, M. A. (2000). Bacterial promoters triggering biodegradation of aromatic pollutants. Curr Opin Biotechnol 11, 467-475.

Dinamarca, M. A., Ruiz-Manzano, A. \& Rojo, F. (2002). Inactivation of cytochrome $o$ ubiquinol oxidase relieves catabolic repression of the Pseudomonas putida GPol alkane degradation pathway. J Bacteriol 184, 3785-3793.

Ferrández, A., García, J. L. \& Díaz, E. (2000). Transcriptional regulation of the divergent paa catabolic operons for phenylacetic acid degradation in Escherichia coli. J Biol Chem 275, 12214-12222.
Finkel, S. E. \& Johnson, R. C. (1992). The FIS protein: it's not for DNA inversion anymore. Mol Microbiol 6, 3257.

Galán, B., Díaz, E., Prieto, M. A. \& Garcia, J. L. (2000). Functional analysis of the small component of the 4-hydroxyphenylacetate 3monooxygenase of Escherichia coli W: a prototype of a new flavin: $\mathrm{NAD}(\mathrm{P}) \mathrm{H}$ reductase subfamily. J Bacteriol 182, 627-636.

Galán, B., Kolb, A., Garcia, J. L. \& Prieto, M. A. (2001). Superimposed levels of regulation of the 4-hydroxyphenylacetate catabolic pathway in Escherichia coli. J Biol Chem 276, 37060-37068.

Galán, B., Kolb, A., Sanz, J. M., García, J. L. \& Prieto, M. A. (2003). Molecular determinants of the $h p a$ regulatory system: the HpaR repressor. Nucleic Acids Res 31, 6598-6609.

Galán, B., García, J. L. \& Prieto, M. A. (2004). The PaaX repressor, a link between penicillin $\mathrm{G}$ acylase and the phenylacetyl-coenzymeA catabolon of Escherichia coli W. J Bacteriol 186, 2215-2220.

González-Gil, G., Bringmann, P. \& Kahmann, R. (1996). FIS is a regulator of metabolism of Escherichia coli. Mol Microbiol 22, 21-29.

González-Gil, G., Kahmann, R. \& Muskhelishvili, G. (1998). Regulation of crp transcription by oscillation between distinct nucleoprotein complexes. EMBO J 17, 2877-2885.

Gralla, J. D. (2005). Escherichia coli ribosomal RNA transcription: regulatory roles for ppGpp, NTPs, architectural proteins and a polymerase-binding protein. Mol Microbiol 55, 973-977.

Hengen, P. N., Batram, S., Stewart, L. \& Scheneider, T. (1997). Information analysis of Fis binding sites. Nucleic Acids Res 25, 4994-5002.

Herrero, M., de Lorenzo, V. \& Timmis, K. N. (1990). Transposon vector containing non-antibiotic selection markers for cloning and stable chromosomal insertion of foreign DNA in gram-negative bacteria. J Bacteriol 172, 6557-6567.

Holtel, A., Marqués, S., Möhler, L., Jakubzik, U. \& Timmis, K. N. (1994). Carbon source-dependent inhibition of $x y l$ operon expression of the Pseudomonas putida TOL plasmid. J Bacteriol 176, 1773-1776.

Kaniga, K., Delor, I. \& Cornelis, G. R. (1991). A wide-host-range suicide vector for improving reverse genetics in Gram-negative bacteria: inactivation of the blaA gene of Yersinia enterocolitica. Gene 109, 137-141.

Kelly, A., Goldberg, M., Carroll, R., Danino, V., Hinton, J. \& Dorman, C. (2004). A global role for FIS in the transcriptional control of metabolism and type III secretion in Salmonella enterica serovar Typhimurium. Microbiology 150, 2037-2053.

Kolb, A., Busby, S., Buc, H., Garges, S. \& Adhya, S. (1993). Transcriptional regulation by cAMP and its receptor protein. Annu Rev Biochem 62, 749-795.

Marschall, C., Labrousse, V., Kreimer, M., Weichart, D., Kolb, A. \& Hengge-Aronis, R. (1998). Molecular analysis of the regulation of csiD, a carbon starvation-inducible gene in Escherichia coli that is exclusively dependent on $\sigma^{\mathrm{S}}$ and requires activation by cAMP-CRP. J Mol Biol 276, 339-353.

Maxam, A. M. \& Gilbert, W. (1977). A new method for sequencing DNA. Proc Natl Acad Sci U S A 74, 560-564.

Miller, J. H. (1972). Experiments in Molecular Genetics. Cold Spring Harbor, NY: Cold Spring Harbor Laboratory.

Moreno, R., Ruiz-Manzano, A., Yuste, L. \& Rojo, F. (2007). The Pseudomonas putida Crc global regulator is an RNA binding protein that inhibits translation of the AlkS transcriptional regulator. Mol Microbiol 64, 665-675.

Nash, H. A., Robertson, C. A., Flamm, E., Weisberg, R. A. \& Miller, H. I. (1987). Overproduction of Escherichia coli integration host factor, a protein with nonidentical subunits. J Bacteriol 169, 4124-4127. 
Nilsson, L. \& Emilson, V. (1994). Factor for inversion stimulationdependent growth rate regulation of individual tRNA species in Escherichia coli. J Biol Chem 269, 9460-9465.

Petruschka, L., Burchhardt, G., Muller, C., Weihe, C. \& Herrmann, H. (2001). The cyo operon of Pseudomonas putida is involved in carbon catabolite repression of phenol degradation. Mol Genet Genomics 266, 199-206.

Prieto, M. A. \& García, J. L. (1994). Molecular characterization of 4hydroxyphenylacetate 3-hydroxylase of Escherichia coli. J Biol Chem 269, 22823-22829.

Prieto, M. A. \& Garcia, J. L. (1997). Identification of a novel positive regulator of the 4-hydroxyphenylacetate catabolic pathway of Escherichia coli. Biochem Biophys Res Commun 232, 759-765.

Prieto, M. A., Pérez-Aranda, A. \& Garcia, J. L. (1993). Characterization of an Escherichia coli aromatic hydroxylase with a broad substrate range. J Bacteriol 175, 2162-2167.

Prieto, M. A., Díaz, E. \& García, J. L. (1996). Molecular characterization of the 4-hydroxyphenylacetate catabolic pathway of Escherichia coli W: engineering a mobile aromatic degradative cluster. J Bacteriol 178, 111-120.

Prieto, M. A., Galán, B., Torres, B., Fernández, A., Miñambres, B., Garcia, J. L. \& Díaz, E. (2004). Aromatic metabolism versus carbon availability: the regulatory network that controls catabolism of less preferred carbon sources in Escherichia coli. FEMS Microbiol Rev 28, 503-518.

Roper, D. I., Fawcett, T. \& Cooper, R. A. (1993). The Escherichia coli C homoprotocatechuate degradative operon: $h p c$ gene order, direction of transcription and control of expression. Mol Gen Genet 237, 241-250.
Ross, W., Thompson, J. F., Newlands, J. T. \& Gourse, R. L. (1990). E. coli Fis protein activates ribosomal RNA transcription in vitro and in vivo. EMBO J 9, 3733-3742.

Saier, M. H., Jr, Chauvaux, S., Deutscher, J., Reizer, J. \& Ye, J. J. (1995). Protein phosphorylation and regulation of carbon metabolism in gram-negative versus gram-positive bacteria. Trends Biochem Sci 20, 267-271.

Saier, M. H., Jr, Chauvaux, S., Cook, G. M., Deutscher, J., Paulsen, I. T., Reizer, J. \& Ye, J. J. (1996). Catabolite repression and inducer control in Gram-positive bacteria. Microbiology 142, 217-230.

Sambrook, J. \& Russell, D. W. (2001). Molecular Cloning. A Laboratory Manual. Cold Spring Harbor, NY: CSHL Press.

Sze, C. C. \& Shingler, V. (1999). The alarmone (p)ppGpp mediates physiological-responsive control at the sigma 54-dependent $P o$ promoter. Mol Microbiol 31, 1217-1228.

Sze, C. C., Moore, T. \& Shingler, V. (1996). Growth phase dependent transcription of the $\sigma^{54}$-dependent Po promoter controlling the Pseudomonas derived (methyl) phenol dmp operon of pVI150. J Bacteriol 178, 3727-3735.

Xu, J. \& Johnson, R. (1995). aldB, an RpoS-dependent gene in Escherichia coli encoding an aldehyde dehydrogenase that is repressed by FIS and activated by CRP. J Bacteriol 177, 3166-3175.

Yuste, L. \& Rojo, F. (2001). Role of the $\operatorname{crc}$ gene in the catabolite repression of the Pseudomonas putida GPol alkane degradation pathway. J Bacteriol 183, 6197-6206.

Edited by: J. Green 